Check for updates

Cite this: RSC Adv., 2019, 9, 19285

Received 14th April 2019

Accepted 21st May 2019

DOI: $10.1039 / c 9 r a 02815 c$

rsc.li/rsc-advances

\section{Influence of defect on the electrical and optical properties of A-site non-stoichiometry $\mathrm{Ca}_{0.67} \mathrm{La}_{0.22} \square_{0.11} \mathrm{Ti}_{(1-x)} \mathrm{Cr}_{x} \mathrm{O}_{3-\delta}$ perovskite}

\author{
A. B. Hassen, ${ }^{a}$ F. I. H. Rhouma, (D) ${ }^{\text {b }}$ M. Daoudi, ${ }^{c}$ J. Dhahri, (DD ${ }^{a}$ M. Zaidi (DD *d \\ and N. Abdelmoula
}

An investigation of the dielectric dispersion, electrical properties, scaling behavior and optical defects of $\mathrm{Ca}_{0.67} \mathrm{La}_{0.22} \square_{0.11} \mathrm{Ti}_{(1-x)} \mathrm{Cr}_{x} \mathrm{O}_{3-\delta}\left(\mathrm{CLT}_{(1-x)} \mathrm{Cr}_{x}\right)$ with $x=0$ and $x=0.1$ compositions is presented. The square in the formula is attributed to a vacancy in A-site. Relaxation phenomena were studied with dielectric and modulus formalism, while, the conductivity mechanism was investigated using electrical conductivity. A high permittivity of around $10^{4}$, low dielectric loss and low electrical conductivity of around $10^{-3} \mathrm{~S} \mathrm{~cm}^{-1}$ for $\mathrm{Ca}_{0.67} \mathrm{La}_{0.22} \mathrm{TiO}_{3}$ (CLT) was observed. These values make this composition interesting for microelectric applications. A comparison between the $Z^{\prime \prime}$ and $M^{\prime \prime}$ indicated that the shortrange carrier motion dominates at low temperature and becomes less localized at high temperature. The optical defects of CLT and $\mathrm{Ca}_{0.67} \mathrm{La}_{0.22} \mathrm{Ti}_{0.9} \mathrm{Cr}_{0.1} \mathrm{O}_{3}\left(\mathrm{CLT}_{0.9} \mathrm{Cr}_{0.1}\right)$ were studied by electron paramagnetic resonance (EPR) spectroscopy. The results suggest the formation of a $\left[\mathrm{TiO}_{6}\right]^{9-}$ center, a $\left(\mathrm{Ti}^{3+}-\mathrm{V}_{\mathrm{O}}\right)$ center, and $\left(V_{\mathrm{Ti}_{\mathrm{i}}^{\prime}}^{\prime}-V_{\mathrm{O}}^{*}\right)^{\cdot}$ dipole defect for CLT compound and $\mathrm{Cr}^{3+}-V_{\mathrm{O}}$ center defect for $\mathrm{CLT}_{0.9} \mathrm{Cr}_{0.1}$ compound. These defects are the source of the in-gap electron traps, which improve the optical properties of $\mathrm{CLT}_{(1-x)} \mathrm{Cr}_{x}$ and hence make it an interesting optical material for different applications.

\section{Introduction}

Solid-oxide electrochemical sensors are one of the most reliable appliances whose most advantageous features are detection of toxic gases. Among these gases, nitrogen oxides $\mathrm{NO}_{X}$ (nitrogen monoxide $\mathrm{NO}$ and nitrogen dioxide $\mathrm{NO}_{2}$ ), which are mainly released from automotive engines, are the most dangerous air pollutants; they are harmful to humans and the environment. ${ }^{1}$ To monitor $\mathrm{NO}_{X}$ emission, lots of efforts have been made to develop high performance and compact solid electrolyte $\mathrm{NO}_{X}$ type sensors with a stable, sensitive, selective and quick response. ${ }^{2-8}$ Yttrium Stabilized Zirconia $\mathrm{Y}_{4 x} \mathrm{Zr}_{1-4 x} \mathrm{O}_{2-2 x}$ (YSZ) has exceptionally high ionic conductivity but only at a temperature beyond $800{ }^{\circ} \mathrm{C}$. Its high operating temperature, however, can lead to many problems; it limits the selection of compatible

${ }^{a}$ Laboratoire de La Matière Condensée et des Nanosciences, Département de Physique, Faculté des Sciences de Monastir, 5019, Tunisia

${ }^{b}$ Laboratoire de Photovoltaïque de Semi-conducteurs et de Nanostructures, Centre de Recherche des Scienes et Technologies de L'Energie, BP. 95, Hammam-Lif 2050, Tunisia

${ }^{c}$ Laboratoire de Recherche Energie et Matière pour Les Développements des Sciences Nucléaire, Centre National des Sciences et Technologie Nucléaires, 2020 SidiThabet, Tunisia

${ }^{d}$ Université de Monastir, Laboratoire de Micro-optoélectroniques et Nanostructures (LMON), Monastir 5000, Tunisia

${ }^{e}$ Laboratory of Multifunctional Materials and Applications (LAMMA), (LR16ES18), Faculty of Sciences of Sfax, University of Sfax, B. P. 1171, 3000, Sfax, Tunisia electrodes and interconnect materials ${ }^{9}$ and reduces the service life of the sensor. ${ }^{10}$ Thus, it is urgent to search for an alternative oxide electrolyte material that can capture $\mathrm{NO}_{X}$ at a mild temperature. In this case, several kinds of perovskite $\left(\mathrm{ABO}_{3}\right)$ solid electrolytes have recently been proposed as optimal materials for $\mathrm{NO}_{X}$ sensors with higher sensing performance, at low and intermediate temperature $\left(\sim 400-600{ }^{\circ} \mathrm{C}\right)$, than that of YSZ. One of the most promising electrolyte materials proposed by Ishihara et al. and by Feng and Goodenough in 1994 is doped lanthanum gallate $\left(\mathrm{LaGaO}_{3}\right)$ such as $\mathrm{La}_{(1-x)} \mathrm{Sr}_{x} \mathrm{Ga}_{(1-y)} \mathrm{Mg}_{y} \mathrm{O}_{3-\delta}$ (LSGM), ${ }^{\mathbf{1 1 , 1 2}}$ whose conductivity at low temperature is higher than those of YSZ. ${ }^{13-15}$ Unfortunately, the use of LSGM as a solid electrolyte has so far been hampered by several issues, such as the difficulty of obtaining pure phase materials, ${ }^{16}$ the volatility of gallium at high temperature and its high reactivity with $\mathrm{Ni}$ (typically used as anode), which greatly limits the application of such sensor in $\mathrm{NO}_{X}$ detection, too. Later, Sinha et al. ${ }^{17}$ examined the calcium-doped $\mathrm{GdAlO}_{3}$ used for $\mathrm{NO}_{X}$ sensor, whereas both response and recovery speed are still slow. Recently, a great amount of experimental data has peaked in favor of A-site nonstoichiometry perovskites notably on sodium bismuth titanate (NBT). Several researches realized by many authors ${ }^{18-23}$ explored the influence of A-site non-stoichiometry on the ionic conductivity in NBT. Li et al. ${ }^{24}$ also reported that $\mathrm{Mg}$-doping $\mathrm{Na}_{0.5^{-}}$ $\mathrm{Bi}_{0.49} \mathrm{Ti}_{0.98} \mathrm{Mg}_{0.02} \mathrm{O}_{2.96}$ revealed a perfect conductivity of up to $\sigma$ $\sim 10^{-2} \mathrm{~S} \mathrm{~cm}^{-1}$ at $600{ }^{\circ} \mathrm{C}$ and predicted the possible application in solid oxide fuel cell and sensor field as electrolyte material. 
Meyer and Albe ${ }^{25}$ discovered that the different phases of NBT have different migration barriers, and the association of oxygen vacancies with migration barriers can be used to describe the change in the activation energy. Doping bismuth with a high rate leads to the total oxygen vacancy $\left(V_{\mathrm{O}}\right)$ concentration. ${ }^{26}$ In this way, already small amounts of defects are sufficient to severely influence the ionic conductivity. ${ }^{27-29}$ More than that, Yang et al. ${ }^{30}$ attributed the high level of oxide-ionic conductivity to the mobility of oxygen ions. Based on these considerations, namely the A-site non-stoichiometric perovskite, the aim of the present work is to investigate the defect chemistry and electrical properties of A-site non-stoichiometric $\operatorname{CLT}_{(1-x)} \mathrm{Cr}_{x}$ ceramics which have an important dielectric and optical behavior related to $V_{\mathrm{O}}{ }^{31}$ and which, furthermore, might account for the application in technology as gas sensor.

\section{Experimental section}

The A-site non-stoichiometry $\operatorname{CLT}_{(1-x)} \mathrm{Cr}_{x}$ ceramics with $x=$ 0 and 0.1 are prepared from high purity (99.9\%) precursors $\mathrm{CaCO}_{3}, \mathrm{La}_{2} \mathrm{O}_{3}, \mathrm{TiO}_{2}$ and $\mathrm{Cr}_{2} \mathrm{O}_{3}$ in powder by using a conventional ceramic-making technique of solid-state reaction. Polycrystalline sample synthesis and its X-ray structure determination by the Rietveld refinement were reported by us elsewhere. ${ }^{31}$ It was found that $\mathrm{CLT}_{(1-x)} \mathrm{Cr}_{x}$ crystallizes in Orthorhombic Pnma structure without any detectable secondary phase.

The dielectric measurements were performed on ceramic disks (of about $8 \mathrm{~mm}$ diameter and $1 \mathrm{~mm}$ thickness) after the deposition of gold electrodes on the circular faces by cathodic sputtering using an impedance analyzer, Wayne-Kerr 6425 (in the frequency range from $20 \mathrm{~Hz}$ to $1 \mathrm{MHz}$ ).

Electron paramagnetic resonance (EPR) measurements were performed at room temperature using an EMX X-band EPR spectrometer (Brucker EMX EPR, Germany) in which the EPR signal was acquired with $2 \mathrm{~mW}$ of power and a spectral width in the field range $0<H<8000$ Gauss. From the resonance fields $H$, determined by the zero-crossing point $(\mathrm{d} p / \mathrm{d} H=0)$, the Landé $g$ factor is deduced using the relation $g=h \nu / \mu_{\mathrm{B}} H$ where $\mu_{\mathrm{B}}$ is the Bohr magneton.

\section{Results and discussion}

\subsection{Dielectric permittivity analysis}

Fig. 1(a and b) shows the frequency dependence of the permittivity for $\mathrm{CLT}_{(1-x)} \mathrm{Cr}_{x}$ ceramics from $500 \mathrm{~K}$ to $650 \mathrm{~K}$ and from $303 \mathrm{~K}$ to $650 \mathrm{~K}$ for $x=0$ and $x=0.1$, respectively. The value of $\varepsilon_{\mathrm{r}}^{\prime}$, for all the samples, increases with decreasing frequency and increasing temperature, indicating a strong dielectric dispersion. In fact, the high value of $\varepsilon_{\mathrm{r}}^{\prime}$ at lows frequencies is mainly attributed to the contribution of electronic, space charges, ionic, and interfacial polarization which are generally accompanied by the appearance of dielectric relaxation. However, at high frequency, $\varepsilon_{\mathrm{r}}^{\prime}$ is independent of temperature and frequency. This independence is due to the inability of electric dipoles to follow the fast variation of the applied electric field. Therefore, the dielectric dispersion observed at low
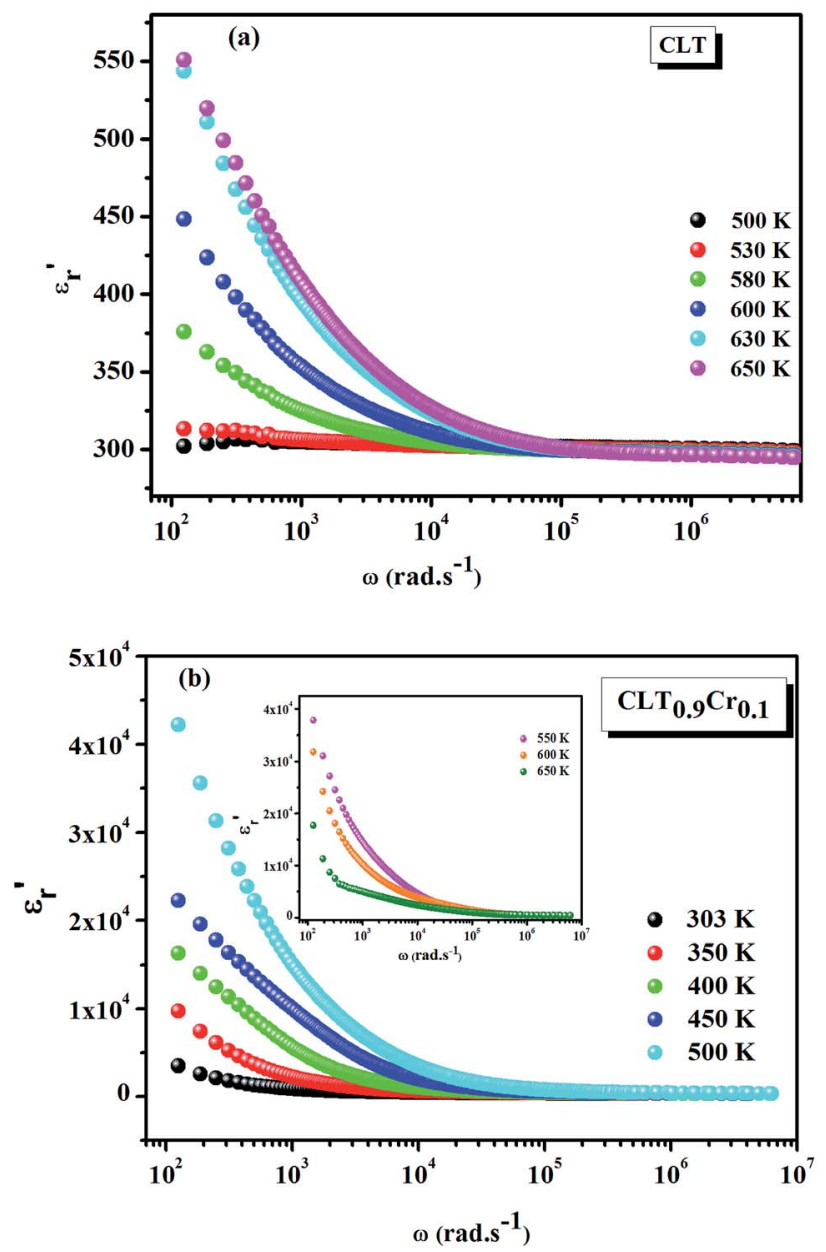

Fig. 1 Frequency and temperature dependence of the real part of permittivity for the compositions (a) $x=0$ and (b) $x=0.1$ solid solution $\mathrm{CLT}_{(1-x)} \mathrm{Cr}_{x}$ ceramics.

frequency range is due to the interfacial polarization, because the electronic and atomic polarizations persist unchanged at this frequency range. ${ }^{32}$ Furthermore, we can note that when chromium is introduced into CLT, a significant rise in the real part of permittivity is seen, suggesting that the variation of $\varepsilon_{\mathrm{r}}^{\prime}$ values results not only from the contribution of thermallyactivated charge defects but also from the dominant effect of chromium-doping. This might be generated by the multivalent configuration of chromium ions. The variation of dielectric loss $(\tan \delta)$ with frequency is shown in Fig. 2. Here angle " $\delta$ " is the phase difference between the applied electric field and the induced current. ${ }^{33}$ Similar to $\varepsilon^{\prime}$, the $\tan \delta$ values decrease with increasing frequency and become constant at higher frequencies. This behavior can be attributed to the decrease in polarization at an applied higher electric field. The observed $\tan \delta$ variation with frequency can be due to the conduction mechanism which is analogous to Koop's phenomenological model. ${ }^{34}$ The $\tan \delta$ curve is considered to be caused by domain wall resonance. At higher frequencies range, losses are found to be low if the domain wall motion is restrained as per Rezlescu model. ${ }^{32,35}$ Moreover, the $\tan \delta$ rises when the polarization lags 

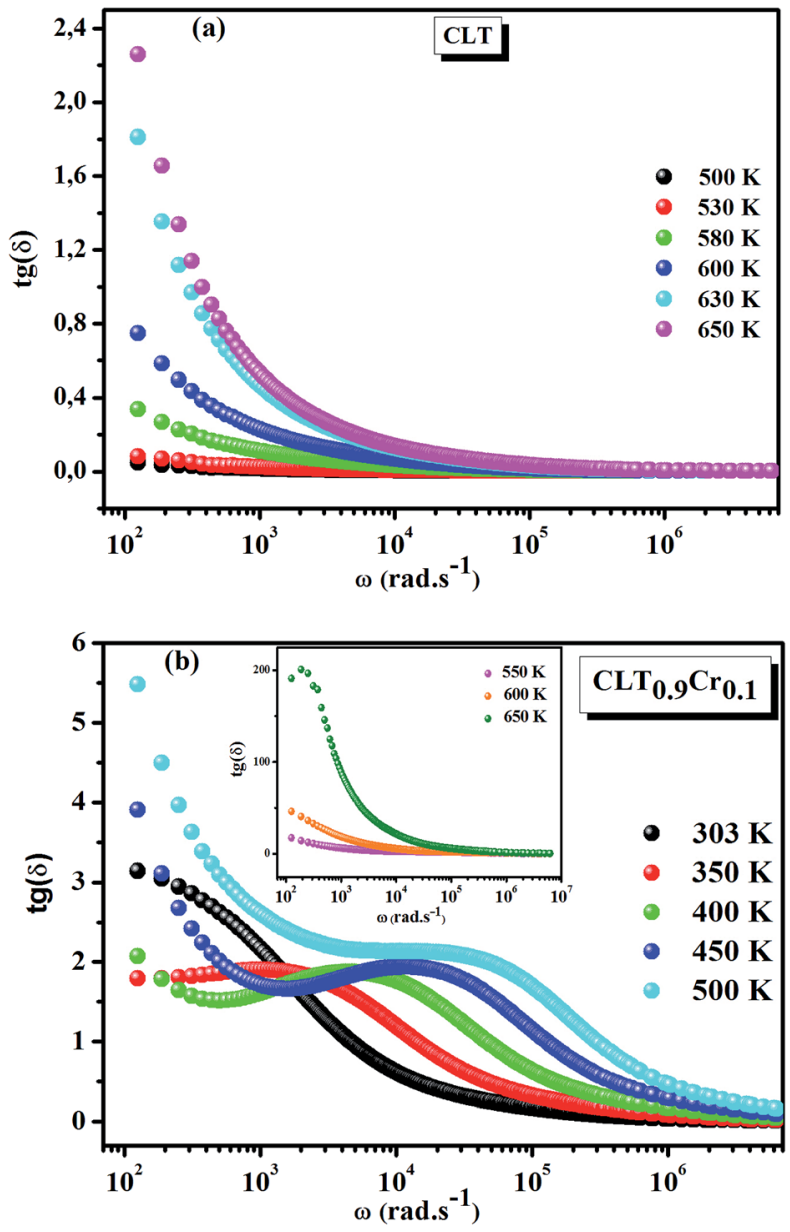

Fig. 2 Frequency and temperature dependence of the dielectric loss $(\tan \delta)$ for compositions (a) $x=0$ and (b) $x=0.1$.

behind the applied alternating electric field. This rise in $\tan \delta$ may also be caused by the grain boundaries, imperfections in the crystal lattice, and impurities. ${ }^{36,37}$ Furthermore, one can see that for the $\mathrm{CLT}_{0.9} \mathrm{Cr}_{0.1}$ composition the $\tan \delta$ curve exhibits a broad peaks with the frequency dispersion at different temperatures. These peaks shift to a higher frequency with increasing temperature, suggesting a typical characteristic of dielectric relaxation phenomenon.

\subsection{Conductivity analysis}

The electrical conductivity is the most common representation for relating the macroscopic measurement to the microscopic movement of the ions. The conductivity of the samples was obtained using the Maxwell relation $\sigma(\omega)=j \omega \varepsilon_{0} \varepsilon^{*}(\omega)$, where $j=\sqrt{-1}, \varepsilon_{0}$ is the vacuum permittivity, and $\varepsilon^{*}(\omega)$ is the complex permittivity. Fundamentally, alternative conductivity $(\sigma(\omega))$ originates from the migration of ions by hopping between neighboring potential wells. It provides insights into different relaxation mechanisms by investigating its frequency and/or temperature dependent response behaviors. Fig. 3(a and b) displays the frequency dependence of $(\sigma(\omega))$ for CLT and $\mathrm{CLT}_{0.9} \mathrm{Cr}_{0.1}$ at various temperatures. The conductivity increases
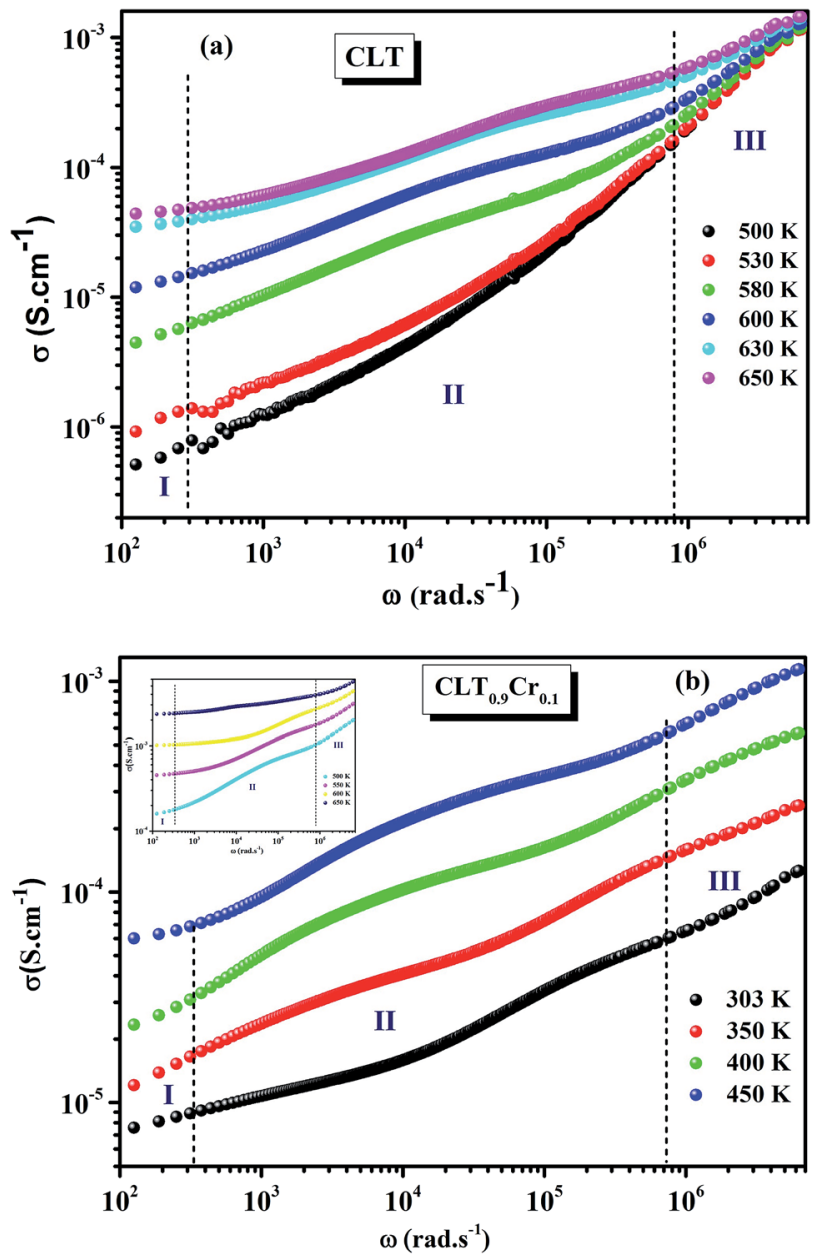

Fig. 3 Variation of conductivity $\sigma(\omega)$ as a function of frequency in a log-log scale at different temperature for $\mathrm{CLT}$ (a) and $\mathrm{CLT}_{0.9} \mathrm{Cr}_{0.1}$ (b) compounds.

with increasing frequency, therefore, it starts from its dc value and eventually attains a "high frequency" plateau at about $10^{6} \mathrm{~Hz}$. More than that, $(\sigma(\omega))$ exhibits a dispersion that shifts to higher frequency with increasing temperatures for all samples. Indeed, the $\sigma(\omega)$ spectrum can be decomposed into three parts: the low frequency (direct conductivity $\left(\sigma_{\mathrm{dc}}\right)$ ) plateau regime (region I), mid-frequency dispersive regime (region II) and high frequency plateau regime (region III). These types of characteristics can be explained on the basis of the jump relaxation model (JRM $)^{38}$ which states that after a hop of a central ion from an initially relaxed local position, it will be no longer in equilibrium with its neighbors. ${ }^{39,40}$ To stabilize the new position of the ion, other ions in its surroundings have to move. However, the ion can also jump back (unsuccessful hop) in order to partially relax the position after the jump. At low frequencies in region I, the frequency is low and the electric field cannot perturb the hopping conduction process of the charged particles. On the contrary, the conductivity is assigned to the successful hops from one localized site to its neighboring vacant site due to the available long time period $(\omega=2 \pi f=2 \pi / T), T$ is the time period, hence, resulting in a long-range motion of ions and 
conductance may be approximated to the dc value in this range. As the frequency increases, the unsuccessful hops increase, since two competing relaxation processes take place, such as; the correlated ion position related to forward backward forward, i.e., unsuccessful hopping and successful hopping wherein the localized orientation hopping in which once jumped ions become relaxed and stay in the new site. Nevertheless, every individual hop is seen when the time window is sufficiently short. This behavior is assigned to the region II. On the other hand, as the ratio of successful to unsuccessful hopping increases, it results in more dispersive conductivity and the increase of conductivity with frequency in region II is thus qualitatively explained. In region III, the rise in conductivity observed in all samples is almost proportional to frequency, resulting in near constant loss (NCL). ${ }^{41}$ Based on JRM, the frequency dependence of the conductivity data was possible to fit (Fig. 4) to a double power law ${ }^{38,42} \sigma(\omega)=\sigma_{\mathrm{dc}}+A \omega^{n_{1}}+B \omega^{n_{2}}$, where $\sigma_{\mathrm{dc}}$ assigned to dc conductivity whose translational hopping gives the long-range electrical transport in the longtime limit, (i.e., at lower frequency). The second term $A \omega^{n_{1}}$, corresponding to the middle region (II) in which the exponent $0<n_{1}<1$ characterizes the low frequency regime, indicates the short range translational hopping motion. The third term $B \omega^{n_{2}}$,
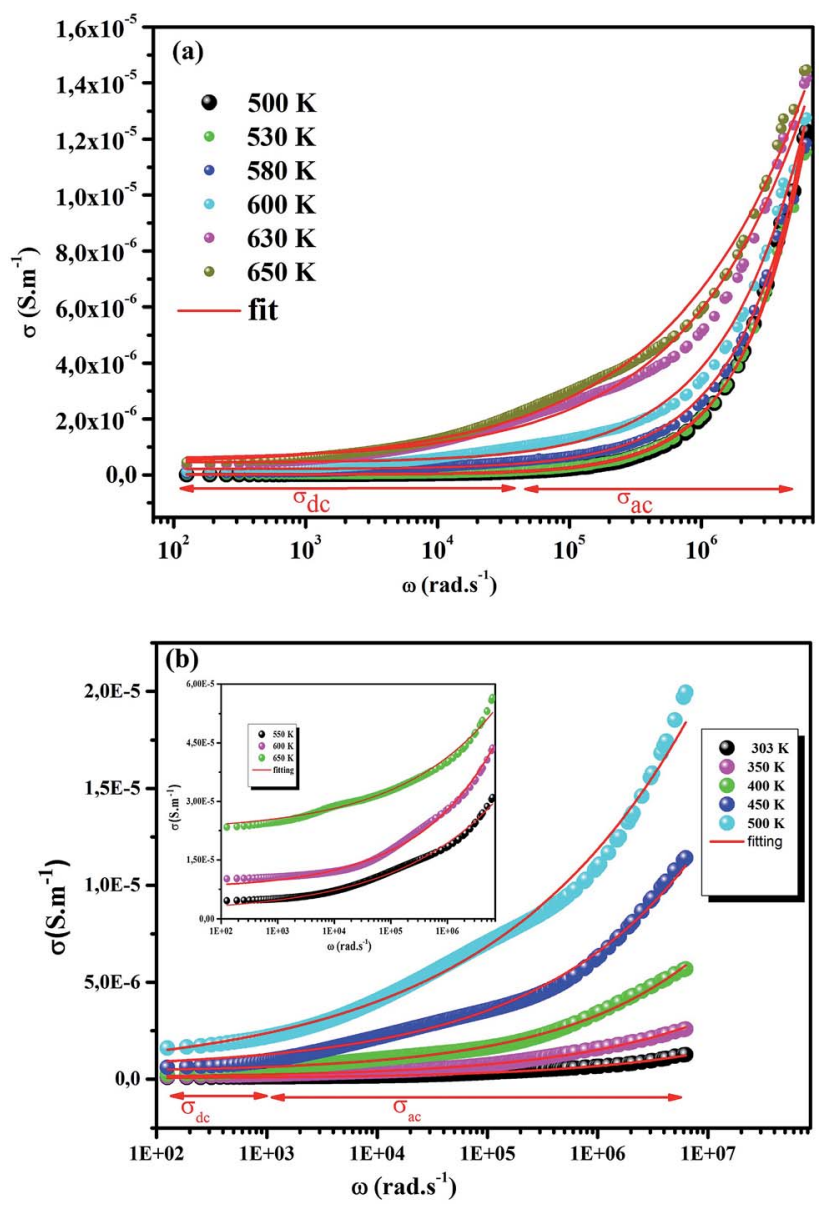

Fig. 4 Frequency dependent of $\sigma(\omega)$ conductivity and its continuous fitting curves using double power law. attributed to the higher frequency region (III) for which the exponent $1<n_{2}<2$, corresponds to localized or reorientation hopping motion. The $n_{1}$ and $n_{2}$ values obtained from the fitting data are shown in Fig. 5(a and b). The $n_{1}$ value exhibits a continuous increase with the temperature, while $n_{2}$ decreases in the measured temperature for all samples. Early reports ${ }^{\mathbf{4 2 , 4 3}}$ predict the dependence of $n$ with the frequency and temperature, where an increase of the exponent values with increasing temperature is assigned to the small polaronic hopping, whereas a decrease in exponent values is ascribed to the large polaronic hopping. From the trend of the exponents behavior with the temperature of CLT and $\mathrm{CLT}_{0.9} \mathrm{Cr}_{0.1}$ compounds, the obtained value of $n_{1}$ was less than 1 and increasing with temperature, which can indicate that the conduction in region II corresponding to the short translational hopping is provided by small polaronic mechanism. On the other hand, in the case of $n_{2}$, the values varied between 1 and 2 and decreased with the temperature, implying that the conduction in region III ascribed to the localized orientation hopping, is assisted by large polaron mechanism. Furthermore, electrical conduction is a thermally activated process and follows the Arrhenius law $\sigma_{\mathrm{dc}}=\sigma_{0} \exp \left(-E_{\mathrm{dc}} / k_{\mathrm{B}} T\right)$, where $\sigma_{0}$ is the pre-exponential term and $E_{\mathrm{dc}}$ represents the activation energies for dc conductivity. As shown in Fig. 6 for CLT and $\mathrm{CLT}_{0.9} \mathrm{Cr}_{0.1}$ compounds, a good
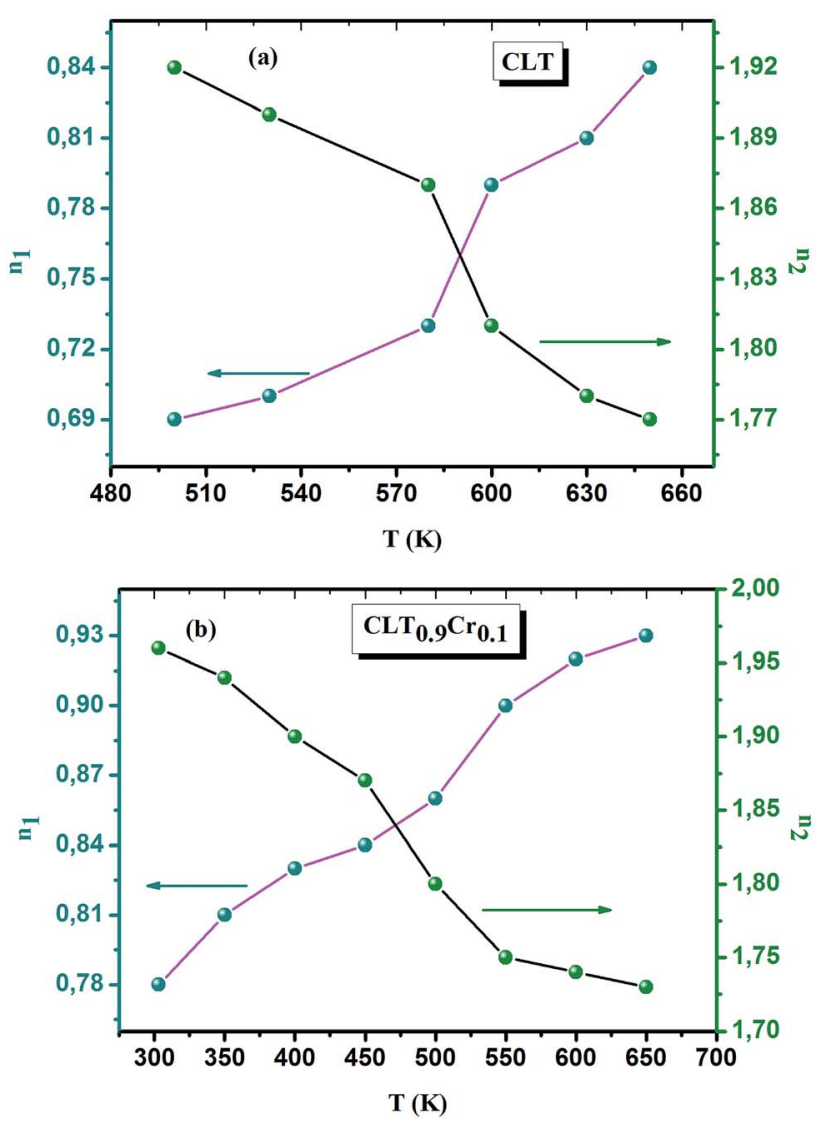

Fig. 5 Double power temperatures parameters $\left(n_{1}, n_{2}\right)$ obtained from the fitting curve of $\sigma(\omega)$ for the compositions (a) $x=0$ and (b) $x=0.1$ solid solution $\mathrm{CLT}_{(1-x)} \mathrm{Cr}_{x}$ ceramics. 
linear fit between $\ln \sigma_{\mathrm{dc}}$ and $1000 / T$ is obtained. The conduction activation energies are $1.08 \mathrm{eV}$ and $0.69 \mathrm{eV}$ for CLT and $0.42 \mathrm{eV}$ and $0.12 \mathrm{eV}$ for $\mathrm{CLT}_{0.9} \mathrm{Cr}_{0.1}$. It is obvious that a slight substitution of chromium for titanium in B-sites reduced the activation energy for electrical conductions in grain boundaries, indicating that it is easier to activate the conducting electrons in our compounds after $\mathrm{Cr}$ substitution. This corresponds to a decrease of grain boundary resistance in Cr-doped samples. More than that, Ang et al. ${ }^{44}$ proposed that in titanate perovskite, the ionization of oxygen vacancy separated two stages and created the conducting electrons, depicted as.

$$
\begin{gathered}
V_{\mathrm{O}} \Leftrightarrow V_{\mathrm{O}}^{\cdot}+e^{\prime} \\
V_{\mathrm{O}}^{\cdot} \Leftrightarrow V_{\mathrm{O}}^{\cdot}+e^{\prime}
\end{gathered}
$$

Or these electrons might be bonded to $\mathrm{Ti}^{4+}$ in the form of $\mathrm{Ti}^{4+}+$ $e^{\prime} \Leftrightarrow \mathrm{Ti}^{3+}$.

The first conduction activation energies at low temperature $(0.69 \mathrm{eV}$ and $0.12 \mathrm{eV})$ and the second at higher temperature are (0.42 $\mathrm{eV}$ and $1.08 \mathrm{eV}$ ) for CLT and $\mathrm{CLT}_{0.9} \mathrm{Cr}_{0.1}$, respectively, are very close to the activation energy value of oxygen vacancies in
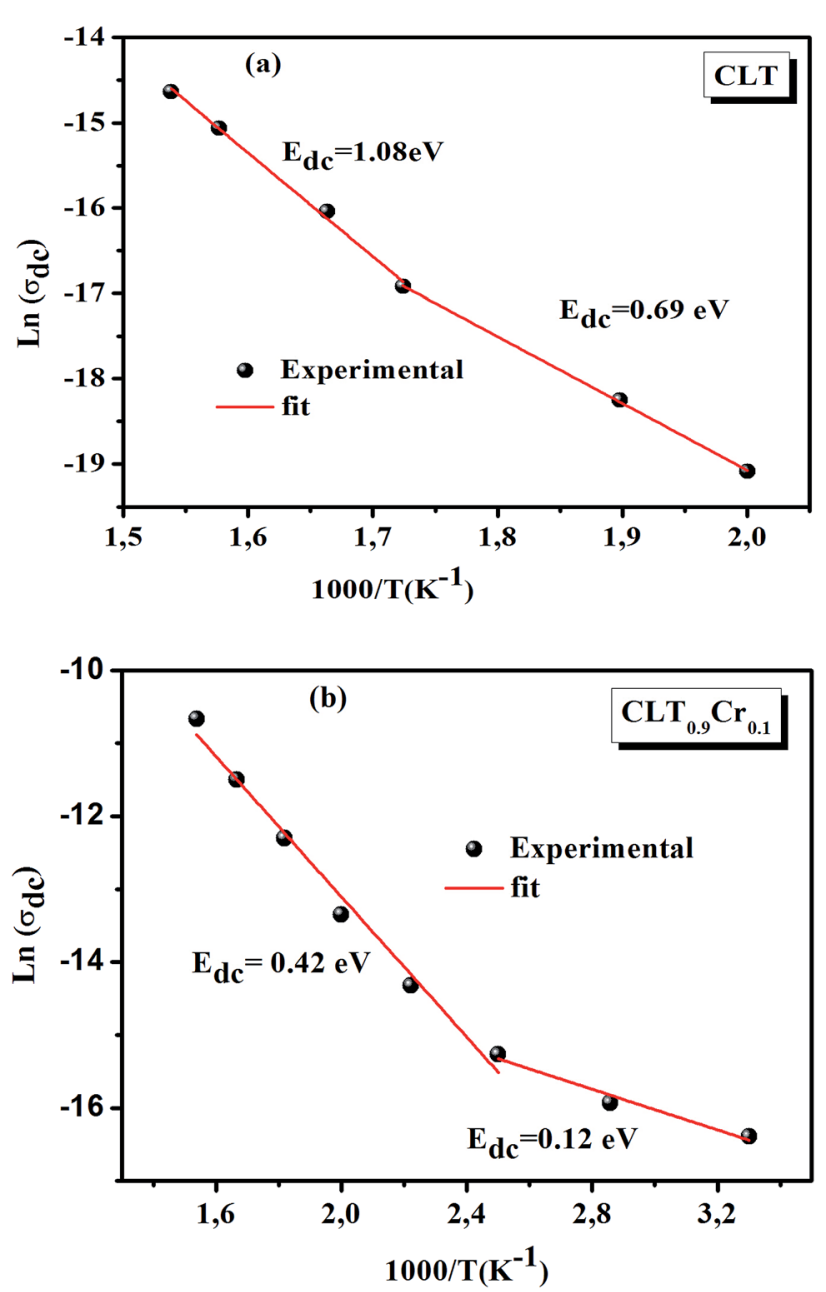

Fig. 6 Arrhenius plots as a function of the temperature, indicating two regions with different activation energies for compositions (a) $x=$ 0 and (b) $x=0.1$. ferroelectric oxides and the values are associated with $V_{\mathrm{O}}^{*}$ and $V_{\mathrm{O}}^{* *}$, respectively. ${ }^{45}$ At low temperatures, the $E_{\mathrm{dc}}$ values indicate that the $V_{\mathrm{O}}^{*}$ and electron hopping are responsible for conduction because these values are much less than that of the $V_{\mathrm{O}}^{\cdot *}{ }^{46}$ At high temperatures, the $E_{\mathrm{dc}}$ values increase, which shows that the electrical conduction is governed by the thermal excitation of carriers from the $V_{\mathrm{O}}^{*}$. One of the conducting electrons is created by the $V_{\mathrm{O}}$ ionization and the other from the valence fluctuation between $\mathrm{Ti}^{3+}$ and $\mathrm{Ti}^{4+}$. The created electrons would be trapped at defects, such as lattice vacancies, boundaries, and dislocations. These electros might hop between the neighboring transition metal ions as $\mathrm{Ti}^{4+}$ and $\mathrm{Ti}^{3+}$. Besides, the low conductivity and high activation energy of the CLT compounds suggest that the elimination of defects, trapped in the grain boundary and electrode-interface, significantly reduces the influence of domain walls and $V_{\mathrm{O}}$ can easily be released out and no space charge is built up.

\subsection{Conductivity scaling}

From $\sigma(\omega)$ spectra, a strong frequency dispersion above the characteristic crossover frequency can be observed and it is found to shift towards higher values with increasing temperature. Besides, it can be seen that the frequency range of the mid frequency plateau region of $\sigma(\omega)$ spectra depends strongly on temperature. These two observations indicate that multiple $\sigma(\omega)$ isotherms can be superimposed to form a single master curve in a process known as the time-temperature superposition principal (TTSP) or scaling. ${ }^{47}$ In this case, different approaches have been proposed to carry out the TTSP and in general the scaling of conductivity spectra is determined by the following equation $^{\mathbf{4 8 , 4 9}}$

$$
\frac{\sigma(\omega)}{\sigma_{\mathrm{dc}}}=F \frac{\omega}{\sigma_{\mathrm{dc}} T},
$$

where $F$ is the scaling parameter. In our study, we adopt the scaling approach, in which the scaling parameter is chosen as. ${ }^{\mathbf{5 0}}$ This scaling approach implies only two directly accessible physical parameters, $\sigma_{\mathrm{dc}}$ and temperature, for the formation of the master curve. The formation of the master curve using the Summerfield scaling approach for CLT and $\mathrm{CLT}_{0.9} \mathrm{Cr}_{0.1}$ composition is shown in Fig. 7. The curves perfect overlap at different temperatures indicates that the ion conduction mechanism in our compounds is independent of temperature ${ }^{51}$ but with a small deviation, at high temperature and in the lowfrequency range, attributed to electrode polarization effects.

\subsection{Electrical modulus analysis}

The electrical modulus formalism $\left(M^{*}\right)$ is a widely used technique to investigate the electrical relaxation phenomena as it helps in understanding the ion conduction mechanism and relaxation processes by suppressing the effects of electrode polarization essentially observed in the low frequency regions. Note that $M^{*}$ scales inversely to the complex permittivity; that is the more the conductivity loss contributes to the permittivity, the less the conductivity loss affects the module. ${ }^{52,53} M^{*}$ is 

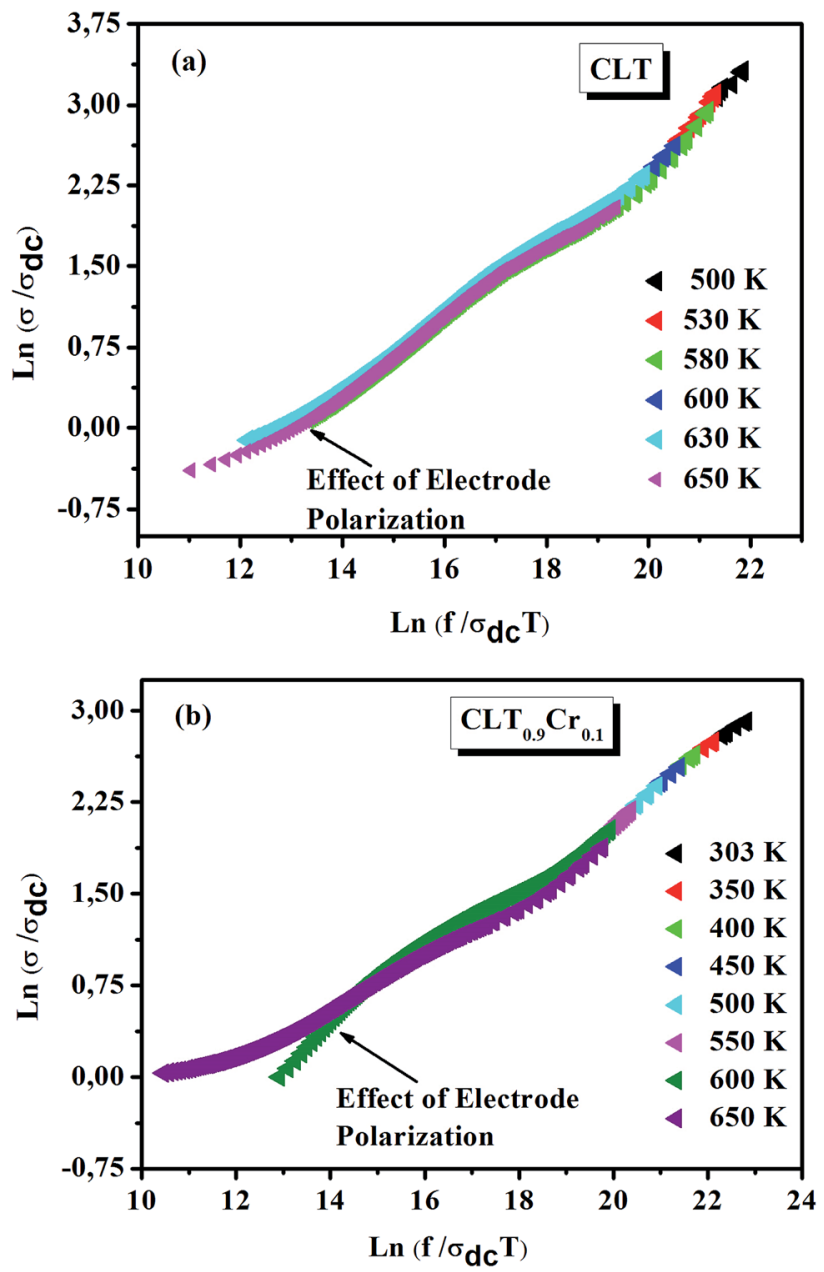

Fig. 7 Scaling behavior of conductivity at various temperatures for compositions (a) $x=0$ and (b) $x=0.1$.

calculated from the dielectric permittivity using the following relation:

$$
M^{*}=\frac{1}{\varepsilon^{*}}=M^{\prime}+\mathrm{i} M^{\prime \prime}=\frac{\varepsilon^{\prime}}{\varepsilon^{\prime 2}+\varepsilon^{\prime \prime 2}}+\mathrm{i} \frac{\varepsilon^{\prime \prime}}{\varepsilon^{\prime 2}+\varepsilon^{\prime 2}}
$$

The frequency dependence of the real and imaginary parts of electrical module spectra $M^{\prime}$ and $M^{\prime \prime}$ at different temperatures of CLT and $\mathrm{CLT}_{0.9} \mathrm{Cr}_{0.1}$ are shown in Fig. 8(a and b). As can be seen $M^{\prime}$ increases gradually with increasing frequency for all compositions. Besides, the composition with $x=0$ presents a saturation even at low frequencies $\left(10^{3} \mathrm{~Hz}\right)$ for low temperatures $(T<580 \mathrm{~K})$ and at high frequency for the other temperature range, which indicates that the electrode polarization phenomena did not contribute and may be ignored when the electric field, are analyzed in this form. ${ }^{54}$ However, for the $\mathrm{CLT}_{0.9} \mathrm{Cr}_{0.1}$ composition, $M^{\prime}$ should get saturation at very high frequency, but due to the frequency limitation of the experimental setup used, we did not observe proper saturation of $M^{\prime}$ spectra. Nonetheless, at very low temperatures and high frequency, $M^{\prime}$ exhibited a nearly saturated behavior. In the case of $M^{\prime \prime}$ spectra, we did observed a distinct peak which corresponds to the conductivity relaxation process. Hence, below the loss peak maximum, the frequency regions determine the range in which charge carriers are mobile (long-range motion). Above this range, however, the carriers are confined to potential wells, being mobile at short distances. Hence, a localized motion was detected here. The frequency region where the peak occurs is indicative of the transition from localized to non-localized mobility with the increase in frequency. This type of behavior of the electrical module is indicative of a temperature-dependent hopping type mechanism for electrical conduction (charge transport) in the system. The values of Full-Width-at-Half-Maxima (FWHM) calculated from the $M^{\prime \prime}$ spectra are greater than 1.144, indicating a spread of relaxation with different time constants and a non-Debye type relaxation. ${ }^{55}$ The relaxation time $\left(\tau^{\mathrm{M}}\right)$ can be defined as the inverse of the maximum module angular frequency $\tau^{\mathrm{M}}=\frac{1}{\omega_{\max }^{\mathrm{M}}}$, with $\omega_{\max }^{\mathrm{M}}$ being the angular frequency where the maximum $M^{\prime \prime}(\omega)$ occurs. $\tau^{\mathrm{M}}$ is found to obey the Arrhenius relation $\tau^{\mathrm{M}}=\tau_{0}^{\mathrm{M}} \exp \frac{E^{\mathrm{M}}}{k_{\mathrm{B}} T}$, where $\tau_{0}^{\mathrm{M}}$ is the pre-exponential factor of the relaxation time and $E^{\mathrm{M}}$ is the relaxation activation energy. $\ln \tau^{\mathrm{M}}$ vs. $(1000 / T)$ is also plotted (inset Fig. 8). The plot exhibits one activation energy for CLT, suggesting one type of probable relaxation process in this composition. However, two activation energies above and below $550 \mathrm{~K}\left(T_{\mathrm{m}}\right.$ for $x=0.1$ (ref. 31)), indicate that two relaxation processes indeed occur in $\mathrm{CLT}_{0.9} \mathrm{Cr}_{0.1}$. The best fittings of $E^{\mathrm{M}}$ were computed for the two samples and are given in Table 1. It is observed that the activation relaxation energy is lower than the activation energy for conduction. This result is explained by the fact that the activation energy for conduction $\left(E_{\mathrm{dc}}\right)$ is the sum of both the creation of charge carriers and their hopping free energy over long range. Whereas, the activation energy for relaxation $\left(E^{\mathrm{M}}\right)$ is equal to the migration free energy of charge carriers and their hopping between the adjacent lattice sites. ${ }^{56}$ The difference between the conduction and relaxation activation energies may be due to the creation of free energy. Relaxation time $(\tau)$ calculated from $M^{\prime \prime}$ is related to the free energy, from the Eyring theory, by the following formula. ${ }^{57}$

$$
\tau=\left(\frac{h}{k_{\mathrm{B}} T}\right) \exp \left(\frac{\Delta F}{R T}\right)
$$

where $\Delta F$ is the free energy of activation for dipole relaxation and $R$ is the constant of perfect gas. Indeed, the enthalpy $(\Delta H)$ and the entropy $(\Delta S)$ are related to $(\Delta F)$ by the relation: $\Delta F=\Delta H$ $-T \Delta S$. This can be expressed as:

$$
\tau=\left(\frac{h}{k_{\mathrm{B}} T}\right) \exp \left(\frac{\Delta H}{R T}\right) \exp \left(-\frac{\Delta S}{R}\right)
$$

$\ln (\tau T)$ versus $1000 / T$ (Fig. 9) was, thus, plotted. $\Delta H$ and $\Delta S$ were fitted to be $5.8428 \mathrm{k} \mathrm{cal} \mathrm{K}^{-1} \mathrm{~mol}^{-1}$ and $-29.0857 \mathrm{cal} \mathrm{mol}^{-1}$ $\mathrm{K}^{-1}$ for $\mathrm{CLT}_{0.9} \mathrm{Cr}_{0.1}$. The negative value for the change in entropy $(\Delta S)$ suggests the existence of dipole-dipole interactions. For a better understanding of the nature of the conductivity relaxation, we presented in Fig. 10 and 11 the combined plots of $Z^{\prime \prime}$ 

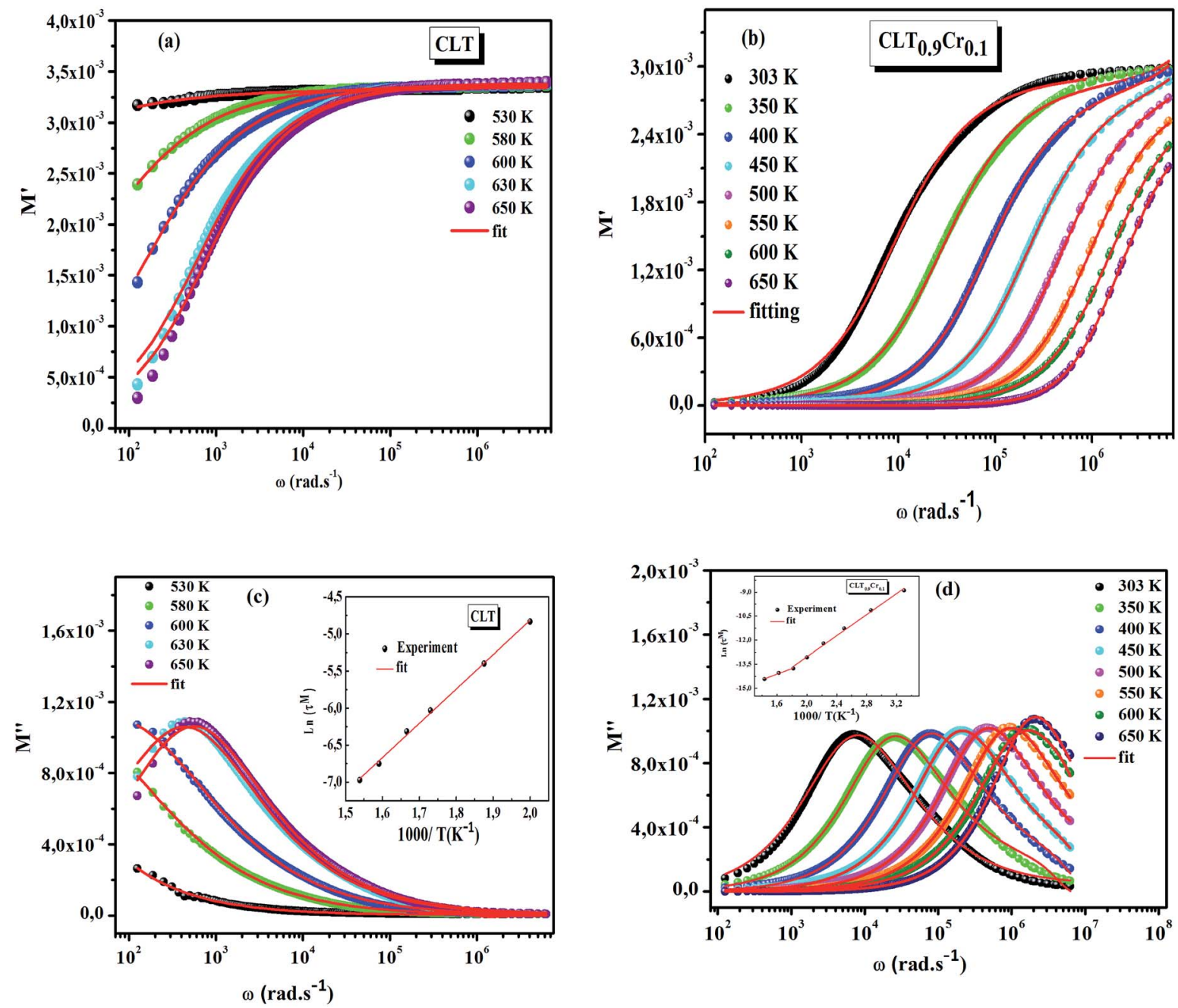

Fig. 8 (a and b) Angular frequency dependence of the real part of electric modulus at several temperatures for compositions (a) $x=0$ and (b) $x=$ 0.1 . ( $c$ and d) Angular frequency dependence of the imaginary part of electric module at several temperatures for compositions (c) $x=0$ and (d) $x$ $=0.1$, the inset shows their corresponding Arrhenius plot of relaxation time $\left(\tau^{\mathrm{M}}\right)$.

Table 1 Activation energy values $\left(E_{\mathrm{a}}\right)$ obtained from the relaxation time plots for different functions: real part of dielectric permittivity, dc conductivity, and electrical modulus

\begin{tabular}{llll}
\hline & \multicolumn{2}{c}{ Activation energy $(\mathrm{eV})$} & \\
\cline { 2 - 3 } Compounds & Dielectric permittivity & dc conductivity & $\begin{array}{l}\text { Electrical } \\
\text { modulus }\end{array}$ \\
\hline CLT & 0.073 & 0.69 & 0.40 \\
& & 1.08 & \\
$\mathrm{CLT}_{0.9} \mathrm{Cr}_{0.1}$ & 0.01 & 0.12 & 0.16 \\
& 0.03 & 0.42 & 0.28
\end{tabular}

and $M^{\prime \prime}$ for CLT and $\mathrm{CLT}_{0.9} \mathrm{Cr}_{0.1}$, respectively, which allows to distinguish between the short-range (i.e. localized: dielectric relaxation) and long-range motion (i.e. non-localized: long range conductivity). ${ }^{58,59}$ We can clearly see that the frequency of the loss peak maximum in the $\left(M^{\prime \prime} / M_{\max }^{\prime \prime}\right)$ slightly shifted to a higher frequency region together with $\left(Z^{\prime \prime} / Z_{\max }^{\prime \prime}\right)$ peak. Moreover, it is known that the relaxation time $\tau_{\mathrm{Z}}$ and $\tau_{\mathrm{M}}$, associated

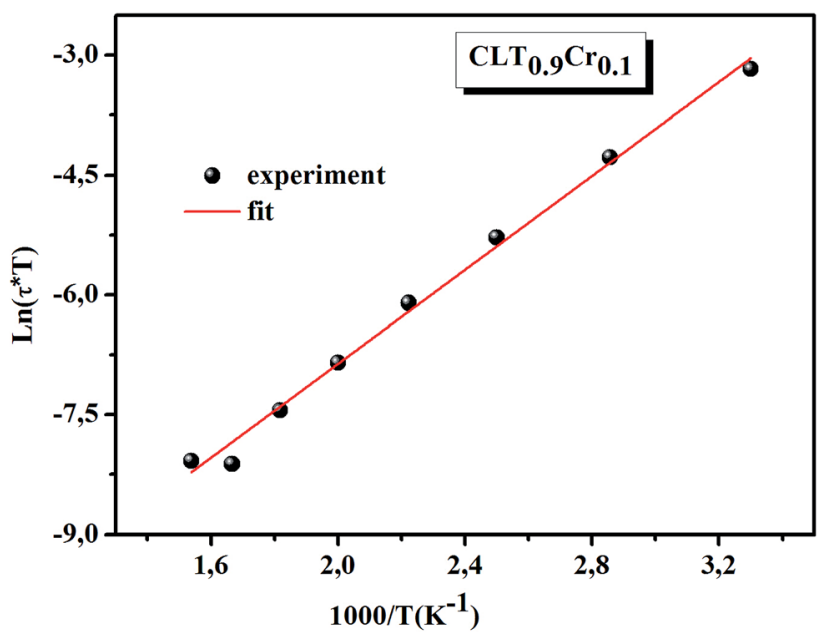

Fig. 9 The temperature dependence of $\ln (\tau T)$. 

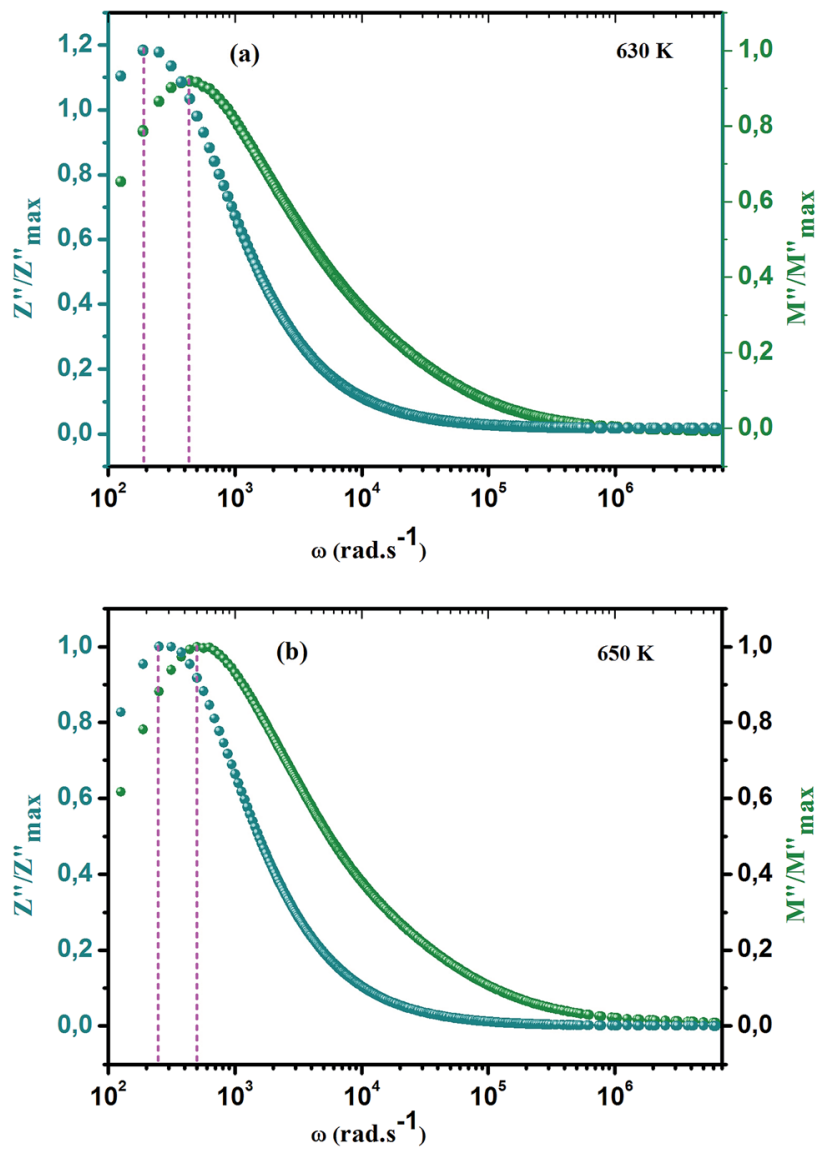

Fig. 10 Angular frequency dependence of $Z^{\prime \prime} / Z_{\max }^{\prime \prime}$ and $M^{\prime \prime} / M_{\max }^{\prime \prime}$ at different temperature for composition ( $\mathrm{a}$ and $\mathrm{b}) \mathrm{x}=0$.

to the two dielectric impedance and electric module, respectively, follows the general order $\tau_{\mathrm{Z}} \geq \tau_{\mathrm{M}}{ }^{.0}{ }^{60}$ That is why the $Z^{\prime \prime}$ maximum appears in a frequency range lower than that of the $M^{\prime \prime}$ maximum peak. The separation between the normalized $M^{\prime \prime}$ and $Z^{\prime \prime}$ loss peak suggests that the current relaxations are dominated by the localized hopping of charge carriers. ${ }^{61,62}$ Furthermore, the frequency gap $(\Delta f)$ between $M^{\prime \prime} / M_{\max }^{\prime \prime}$ and $Z^{\prime \prime} / Z_{\max }^{\prime \prime}$ peaks decreased when temperature increased. This behavior indicates that the conduction process became less localized and translated to non-localized i.e. long-range motion. This proves that the oxygen ions or vacancies contribute to the dc conductivity at high temperatures. Fig. 12(a and b) shows the scaling behaviors of the electric module for the samples with $x$ $=0$ and $x=0.1$, respectively. We can say that the peaks almost collapsed into one curve for $\mathrm{CLT}_{0.9} \mathrm{Cr}_{0.1}$, this shows that the dynamic process of both charge carriers for this composition is temperature independent. However, for sample with $x=0$, it can be noted that the peaks almost collapsed into two curves above and below $T=600 \mathrm{~K}$, suggesting that the dynamic mechanism of charge carriers for CLT is temperature dependent.

\subsection{Electronic paramagnetic resonance analysis}

The main focus in this work is to understand the interrelationships among A-site non-stoichiometry, defect equilibria, and transport properties in the perovskite solid solution of $\mathrm{LT}_{(1-x)} \mathrm{Cr}_{x}$. The EPR technique was used to identify the paramagnetic center (PC) and to investigate defects species in perovskite materials. A phenomenological spin Hamiltonian for PC having an electron spin $S$, a nuclear spin $I$ and the magnetic hyperfine interaction constant $A$ is

$$
H_{\mathrm{B}}=\mu_{\mathrm{B}} S g B_{0}-g_{\mathrm{n}} \mu_{\mathrm{n}} B_{0} I+S A I
$$

where $\mu_{\mathrm{B}}$ denotes the Bohr magneton, $\mu_{\mathrm{n}}$ the nuclear magneton, $B_{0}$ the external magnetic field, $g$ is the electron $g$-matrix and $g_{\mathrm{n}}$ the nuclear $g$-matrix. The first two terms describe the electronic and nuclear Zeeman interaction, respectively, and the third term represents the hyperfine interaction between electron spin and the nuclear spin. ${ }^{63}$ The resonance condition with the applied microwave field $(h \nu)$ was achieved when: $h \nu=g \mu_{\mathrm{B}} B$, where $h$ is Planck's constant (6.626 $\left.910^{-34} \mathrm{~J} \mathrm{~s}\right)$ and $\nu$ is the microwave frequency $(9.815687 \mathrm{GHz})$. Fig. 13(a) shows the EPR spectrum of CLT which exhibits a resonance signal at $g=$ 2.1265, 2.0923, 2.0755, 2.0452, 2.0257, 1.9974, 1.9761, 1.9564, 1.9288 and 1.8812. The intense resonance signal at $g=2.1265$, 2.0923 and 2.0755 is bigger than that of free electron $\left(g_{\mathrm{e}}=\right.$ 2.0023), ${ }^{64,65}$ it originated from surface trapping site according to Shivram et al. ${ }^{66}$ Moreover, Bärner et al. ${ }^{67}$ attributed these signals $(g=2.1265,2.0923$ and 2.0755) to the trapped single electrons located in oxygen vacancies sites $\left(V_{\mathrm{O}}^{\prime}\right)$. These $V_{O}^{\prime}$ are linked to $\mathrm{TiO}_{5}$ clusters, called $\left[\mathrm{TiO}_{5}-V_{\mathrm{O}}^{\prime}\right]$ oxygen complex clusters. ${ }^{68}$ The paramagnetic center at $g=2.0452$ is due to $\mathrm{O}^{-}$free radical. ${ }^{69,70}$ The sharp signal at $g=2.0257$ is probably attributed to an electron shared among the six octahedral oxygen orbits surrounding $\mathrm{B}$-site, i.e., $\left[\mathrm{TiO}_{6}\right]^{9-}$ center. ${ }^{66} \mathrm{~A}$ similar result is observed by Boutinaud et al. ${ }^{71}$ Based on the researches realized by Kutty el al, the resonance signal associated to $g=1.9971$ corresponds to the paramagnetic state due to chemistry defects (e.g. non-stoichiometric A-site).$^{72,73}$ Kutty et al. ${ }^{73}$ assumed that EPR signal at $g=1.9971$ is due to singly ionized A-site. The second strategy assumes that, when the ratio $\frac{\mathrm{Ca}}{\mathrm{Ti}}<1$, excess $\mathrm{Ti}^{4+}$ ions occupy A-site. To satisfy the electro-neutrality, calcium vacancies should be formed in the vicinity of the $\mathrm{Ti}^{4+}$ ion at the $\mathrm{Ca}^{2+}$ site. In this case, a singlet EPR signal arises when the calcium vacancy releases one electron or the $\mathrm{Ti}^{4+}$ ion at the $\mathrm{Ca}^{2+}$ site captures one or two electrons. The paramagnetic center at $g$ $=1.9761$ is attributed to the presence of $\mathrm{Ti}^{3+}$ related defect centers $\left(\mathrm{Ti}^{3+}-V_{\mathrm{O}}\right) \cdot{ }^{73}$ These defect centers are commonly observed in $\mathrm{BaTiO}_{3}$ reducing conditions. ${ }^{64}$ In contrary, Sun et al., however, assign the signal at $g=1.976$ to the presence of Ba (Asite) vacancies. ${ }^{74}$ Nevertheless, there are some important differences between the compositions in our study and those in Sun's work ${ }^{74}$ Sun identified the defect associated with Nddoped $\mathrm{BaTiO}_{3}$, whereas the composition in this study was lanthanum (La) doped calcium titanate $\left(\mathrm{CaTiO}_{3}\right)$ on the A-site. The paramagnetic center resonance at $g=1.9464$, based on the results of Eichel et al. ${ }^{64}$ which showed that $>1.93$, is associated with an $\left(V_{\mathrm{Ti}}^{\prime}-V_{\mathrm{O}}^{*}\right)^{\cdot}$ dipole defect. However, a study by Erdem et al. indicated that when $g>1.91$, the paramagnetic center defect is associated with $\left(V_{\mathrm{Ti}}^{\prime}-V_{\mathrm{O}}^{*}\right)^{\cdot}$ dipole defect. ${ }^{75}$ 

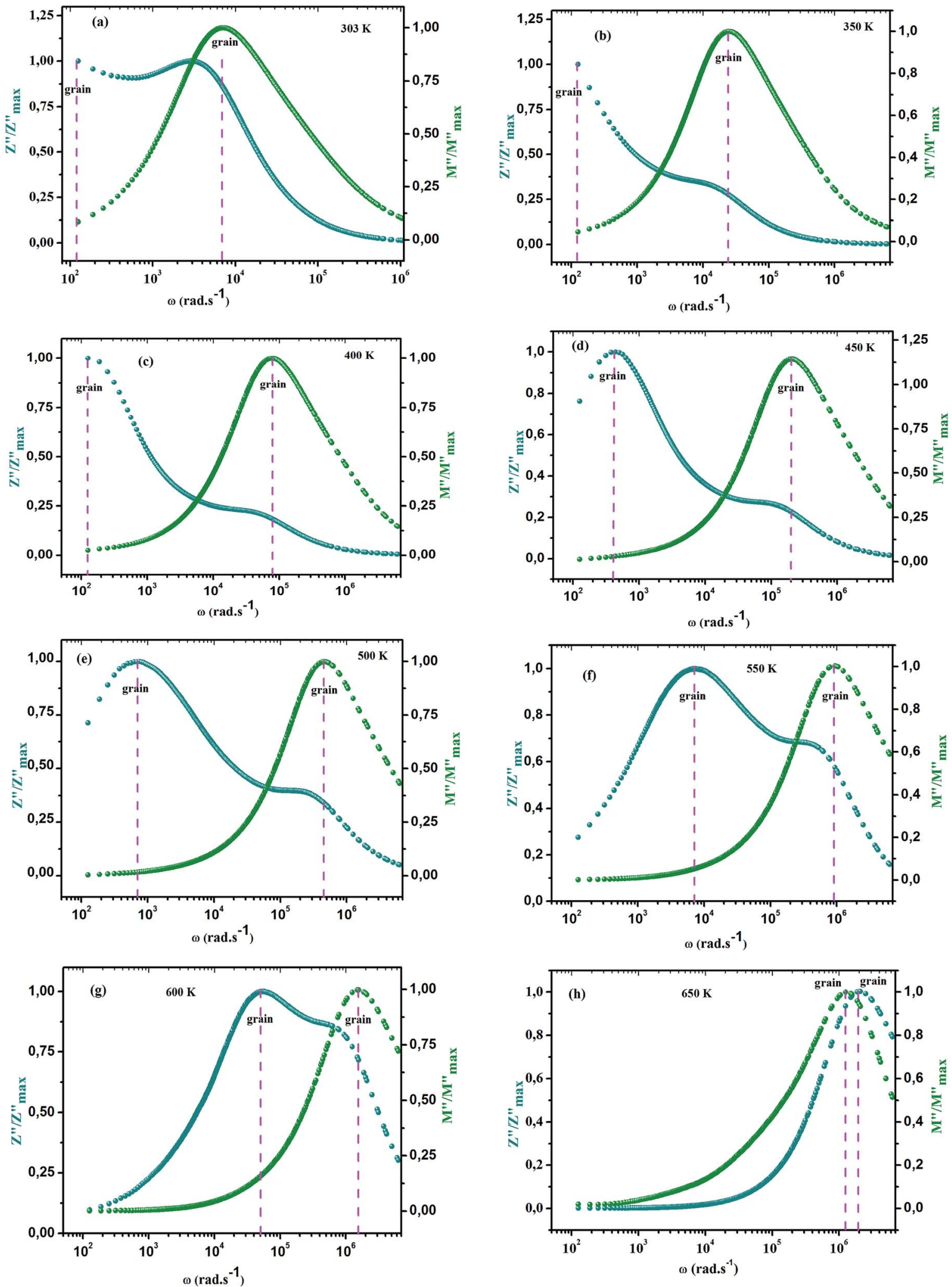

Fig. 11 Angular frequency dependence of $Z^{\prime \prime} / Z_{\max }^{\prime \prime}$ and $M^{\prime \prime} / M_{\max }^{\prime \prime}$ at different temperature for composition (a-h) $x=0.1$.

Taking into account this last result shown in ref. 45 , the signal at $g=1.9288$ is due to the $\left(V_{\mathrm{Ti}}^{\prime}-V_{\mathrm{O}}^{* *}\right)^{*}$ defects dipoles. Nonetheless, Scharschwerdt et al. demonstrated that the signal
1.920-1.9337 is due to $\mathrm{Ti}^{3+}-V_{0}{ }^{76}$ The last signal observed in CLT spectrum is at $g=1.8812$. This paramagnetic signal is due to surface hole trapping sites. ${ }^{77}$ Fig. 13(b) shows the EPR spectrum 

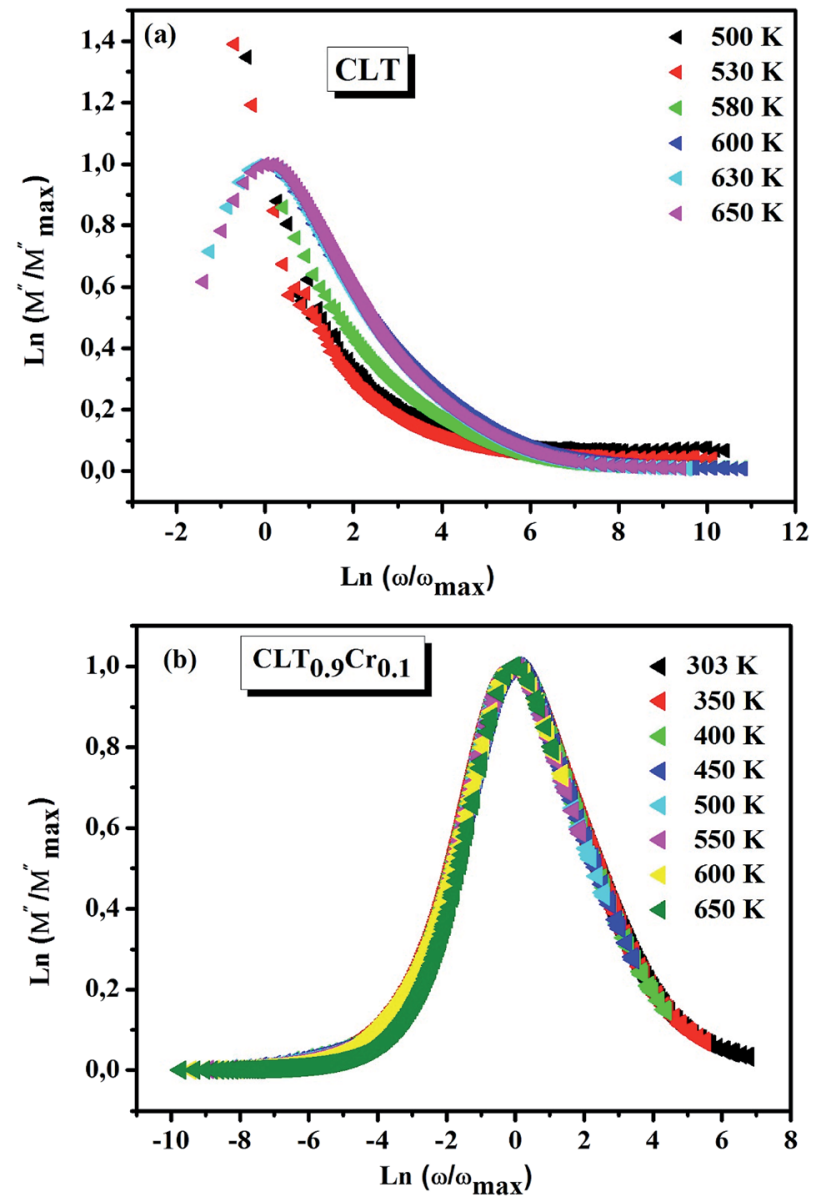

Fig. 12 Scaling behavior of imaginary part of electrical module versus $\ln \left(\omega / \omega_{\max }\right)$ for compositions (a) $x=0$ and (b) $x=0.1$.

of $\mathrm{CLT}_{0.9} \mathrm{Cr}_{0.1}$. The spectra can be described by the spin Hamiltonian. ${ }^{78}$

$$
H_{\mathrm{B}}=\mu_{\mathrm{B}} g H S+D\left\{S_{\mathrm{Z}}^{2}-\frac{1}{3} S(S+1)\right\}+E\left({S_{x}}^{2}-S_{y}{ }^{2}\right)+A S I
$$

With $S=\frac{3}{2}, I=0$ for $\mathrm{Cr}$ isotopes with even mass number, and $I=\frac{3}{2}$ for ${ }^{53} \mathrm{Cr}$. It can be noted that a slight substitution of chromium for titanium in B-sites has considerable effects. $\mathrm{Cr}^{4+}$ has spin $S=1$ and silent EPR. ${ }^{79}$ Moreover, all paramagnetic centers, observed in CLT disappeared, and a new resonance signal at $g=1.9795$ arose. This paramagnetic center is attributed, according to La Mattina et al. ${ }^{80}$ to $3+$ state of the ${ }^{50} \mathrm{Cr},{ }^{52} \mathrm{Cr}$ and ${ }^{54} \mathrm{Cr}$ isotopes $(I=0)$, despite the absence of the signal due to the hyperfine quartet caused by the nuclear-spin coupling $\left(I_{\mathrm{n}}=\frac{3}{2}\right)$ of the ${ }^{53} \mathrm{Cr}$ isotope. ${ }^{80}$ In addition, Azamat et al. assumed that the single signal at $g=1.9788$ is due to the $\mathrm{Cr}^{3+}$ $V_{\mathrm{O}}$ centers. ${ }^{81}$ The slight change in the value of $g$ in different systems is related to differences in the method of synthesis, chemical environment and heat treatment conditions.
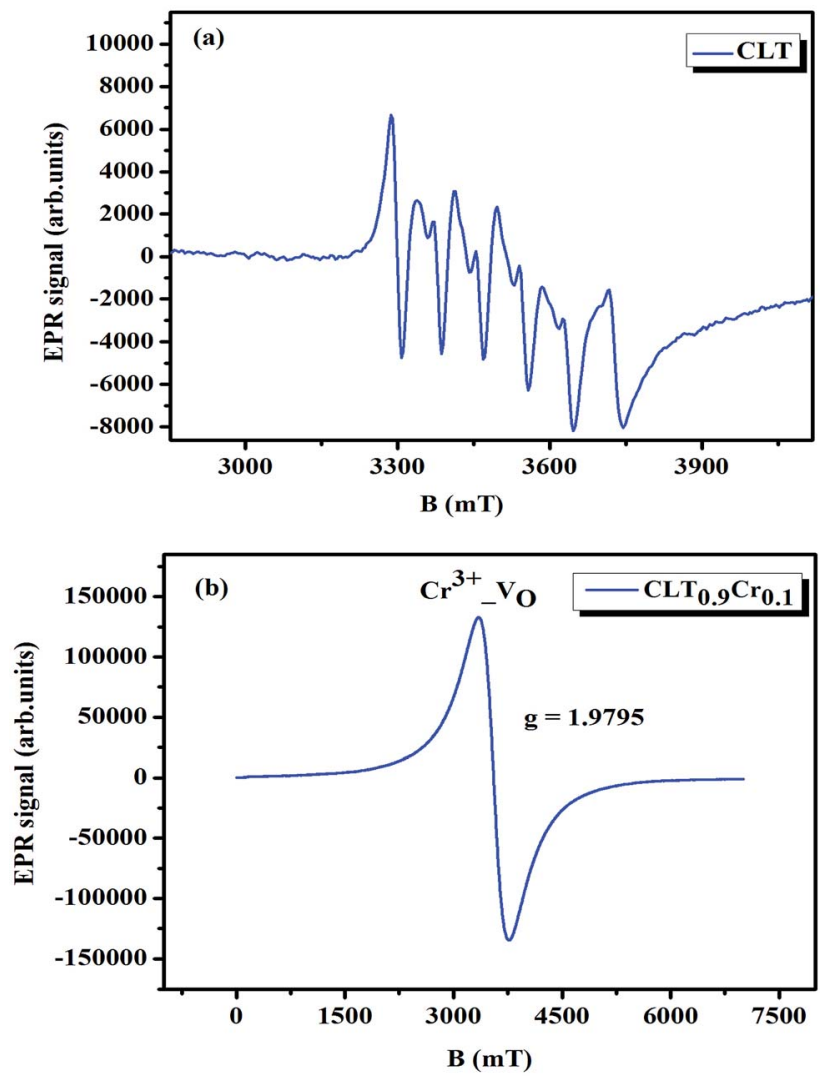

Fig. 13 Room temperature EPR spectra of $\mathrm{CLT}_{(1-x)} \mathrm{Cr}_{x}$ with (a) $x=0.0$ and (b) $x=0.1$.

\section{Conclusion}

A descriptive report on detailed investigation of dielectric, electrical and optical properties of the lead free $\operatorname{CLT}_{(1-x)} \mathrm{Cr}_{x}$ has been presented. It was observed that the dispersion dielectric behavior was dominated in the low frequency range, whereas the resonance dielectric behavior was found to be dominating at higher frequency. Electrical conductivity was described by the jump relaxation model. Three conductivity channels were identified and were found to obey well the double power law, exponent values $\left(n_{1}<1\right)$ and $\left(n_{2}<2\right)$, indicating the different mobile charge species contribution to conductivity. A comparative study of the normalized relaxation peaks corresponding to $Z^{\prime \prime}$ and $M^{\prime \prime}$ showed the coexistence of localized and delocalized motion of charges carriers. Scaling behavior revealed that electrical conduction and dielectric relaxation mechanisms are temperature independent. The EPR study showed several types of paramagnetic point defects in CLT and one defect center corresponding to $\mathrm{Cr}^{3+}-V_{\mathrm{O}}$ center in $\mathrm{CLT}_{0.9} \mathrm{Cr}_{0.1}$.

\section{Conflicts of interest}

There are no conflicts to declare.

\section{References}

1 D. Li, L. Meng, S. Dang, D. Jiang and W. Shi, J. Alloys Compd., 2017, 690, 1-7. 
2 X. Zhang, M. Ikram, Z. Liu, L. Teng, J. Xue, D. Wang, L. Li and K. Sh, RSC Adv., 2019, 9, 8768-8777.

3 S. Cai, S. Yu, W. Wan, W. Wen and Y. Zhou, RSC Adv., 2017, 7, 27397-27404.

4 T. Ueda, M. Sakai, K. Kai, T. Hyodo and Y. Shimizu, Sens. Actuators, B, 2016, 237, 247-255.

5 L. Wu, J. Xia, W. Shi, D. Jiang and Q. Li, Ionics, 2016, 22, $927-$ 934.

6 L. Wang, B. Han, Z. Wang, L. Dai and H. Zhou, Sens. Actuators, B, 2015, 207, 791-800.

7 Y. Yan, S. Krishnakumar, H. Yu, S. Ramishetti, L.-W. Deng, S. Wang, L. Huang and D. Huang, J. Am. Chem. Soc., 2013, 135, 5312.

8 Y. Yan, J. Sun, K. Zhang, H. Zhu, H. Yu, M. Sun, D. Huang and S. Wang, Anal. Chem., 2015, 87, 2087.

9 J. M. Reyes, H. Tiznado, G. Soto, M. V. Bautista, D. Dominguez, E. Murillo, D. Sweeney and J. Read, J. Mater. Sci.: Mater. Electron., 2018, 29, 15349.

10 K. Mahendraprabhu and P. Elumalai, RSC Adv., 2015, 5, 24126-24131.

11 T. Ishihara, H. Matsuda and Y. Takata, J. Am. Chem. Soc., 1994, 116, 3801.

12 M. Feng and J. B. Goodenough, Eur. J. Solid State Inorg. Chem., 1994, T31, 663.

13 S. W. Tao, J. T. S. Irvine and J. A. Kilner, Faraday Discuss., 2007, 9, 134.

14 A. Orera and P. R. Slater, Chem. Mater., 2010, 22, 675.

15 R. C. Biswal and K. Biswas, Int. J. Hydrogen Energy, 2015, 40, 509.

16 A. Matraszek, L. Singheiser, D. Kobertz, K. Hilpert, M. Miller, O. Schulz and M. Martin, Solid State Ionics, 2004, 166, 343.

17 A. Sinha, B. P. Sharma and P. Gopalan, Electrochim. Acta, 2006, 51, 1184.

18 R. Zuo, S. Su, Y. Wu, J. Fu, M. Wang and L. Li, Mater. Chem. Phys., 2008, 110, 311.

19 Y. S. Sung, J. M. Kim, J. H. Cho, T. K. Song, M. H. Kim, H. H. Chong, T. G. Park, D. Do and S. S. Kim, Appl. Phys. Lett., 2010, 96, 022901.

20 Y. S. Sung, J. M. Kim, J. H. Cho, T. K. Song, M. H. Kim and T. G. Park, Appl. Phys. Lett., 2011, 98, 012902.

21 M. Li, M. J. Pietrowski, R. A. De Souza, H. Zhang, I. M. Reaney, S. N. Cook, J. A. Kilner and D. C. Sinclair, Nat. Mater., 2013, 13, 31.

22 M. Naderer, T. Kainz, D. Schütz and K. Reichmann, J. Eur. Ceram. Soc., 2014, 34, 663.

23 M. Li, H. Zhang, S. N. Cook, L. Li, J. A. Kilner, I. M. Reaney and D. C. Sinclair, Chem. Mater., 2015, 27, 629.

24 M. Li, M. J. Pietrowski, R. A. De Souza, H. Zhang, I. M. Reaney, S. N. Cook, J. A. Kilner and D. C. Sinclair, Nat. Mater., 2014, 13, 31.

25 K.-C. Meyer and K. Albe, J. Mater. Chem. A, 2017, 5, 4368.

26 K. Reichmann, A. Feteira and M. Li, Materials, 2015, 8, 5469.

27 X. Liu, H. Fan, J. Shi, L. Wang and H. Du, RSC Adv., 2016, 6, 30623.

28 J. Huang, F. Zhu, D. Huang, B. Wang, T. Xu, X. Li, P. Fan, F. Xia, J. Xiao and H. Zhang, Ceram. Int., 2016, 42, 16798.
29 F. Yang, P. Wu and D. C. Sinclair, Solid State Ionics, 2017, 299, 38.

30 F. Yang, M. Li, L. Li, P. Wu, E. Pradal-Velázquez and D. C. Sinclair, J. Mater. Chem. A, 2018, 6, 5243.

31 A. B. Hassen, F. I. H. Rhouma, J. Dhahri and N. Abedlmoula, J. Alloys Compd., 2016, 663, 436.

32 R. C. Kambale, P. A. Shaikh, C. H. Bhosale, K. Y. Rajpure and Y. D. Kolekar, Smart Mater. Struct., 2009, 18, 115028.

33 Y. D. Kolekar, L. J. Sanchez and C. V. Ramana, J. Appl. Phys., 2014, 115, 144106.

34 C. G. Koops, Phys. Rev., 1951, 83, 121.

35 A. M. Bhavikatti, S. Kulkarni and A. Lagashetty, Int. J. Eng. Sci. Technol., 2014, 3, 5985.

36 G. H. Jonker, J. Phys. Chem. Solids, 1959, 9, 165.

37 S. Mahalakshmi, M. K. Srinivasa and S. Nithiyanantham, J. Supercond. Novel Magn., 2014, 27, 2083.

38 N. Ortega, A. Kumar, P. Bhattacharya, S. B. Majumder and R. S. Katiyar, Phys. Rev. B: Condens. Matter Mater. Phys., 2008, 77, 014111.

39 A. Bettaibi, R. Jemai, M. A. Wederni, R. M'nassri, M. Barbouche, H. Rahmouni and K. Khirouni, RSC Adv., 2017, 7, 22578.

40 W. Li and R. W. Schwartz, Appl. Phys. Lett., 2006, 89, 242906. 41 A. Pelaiz-Barramco, M. P. Gutierrez-Amador, A. Huanosta and R. Valenzuela, Appl. Phys. Lett., 1998, 73, 2039.

42 S. R. Elliott, Adv. Phys., 1987, 36, 135.

43 S. Chouchene, K. Jaoudi, T. Mhiri, N. Zouari and A. Daoud, Ionics, 2017, 23, 169.

44 C. Ang, Z. Yu and L. E. Cross, Phys. Rev. B: Condens. Matter Mater. Phys., 2000, 62, 228.

45 F. Rehman, H. Jin and J. Li, RSC Adv., 2016, 6, 35102.

46 J. Wu and J. Wang, J. Am. Ceram. Soc., 2010, 93, 2795.

47 S. Das and A. J. Bhattacharyya, J. Phys. Chem. Lett., 2012, 3, 3550-3554.

48 S. N. Tripathy, Z. Wojnarowska, J. Knapik, H. Shirota, R. Biswas and M. Paluch, J. Chem. Phys., 2015, 142, 184504.

49 S. Murugavel and B. Roling, Phys. Rev. Lett., 2002, 89, 195902.

50 S. Das and A. J. Bhattacharyya, J. Phys. Chem. Lett., 2012, 3, 3550.

51 A. Pan and A. Ghosh, Phys. Rev. B: Condens. Matter Mater. Phys., 2002, 66, 12301.

52 Q. Ke, X. Lou, Y. Wang and J. Wang, Phys. Rev. B: Condens. Matter Mater. Phys., 2010, 82, 024102.

53 A. E. Stearn and H. Hyring, J. Chem. Phys., 1937, 5, 113.

54 N. Ortega, A. Kumar, P. Bhattacharya, S. B. Majumder and R. S. Katiyar, Phys. Rev. B: Condens. Matter Mater. Phys., 2008, 77, 014111.

55 G. Molnár, S. Cobo, T. Mahfoud, E. J. M. Vertelman, P. J. van Koningsbruggen, P. Demont and A. Bousseksou, J. Phys. Chem. C, 2009, 113, 2586.

56 I. W. Kim, C. W. Ahn, J. S. Kim, J. S. Bae, B. C. Choi, J. H. Jheong and J. S. Lee, Appl. Phys. Lett., 2002, 80, 4006.

57 A. V. Sarode and A. C. Kumbharkhane, J. Mol. Liq., 2011, 164, 226.

58 J. J. Liu, Phys. Rev. B: Condens. Matter Mater. Phys., 2004, 70, 144106.

59 M. A. L. Nobre and S. Lanfredi, J. Appl. Phys., 2003, 93, 5576. 
60 W. Bai, G. Chen, J. Y. Zhu, J. Yang and T. Lin, Appl. Phys. Lett., 2012, 100, 082902.

61 Q. Ke, X. Lou, Y. Wang and J. Wang, Phys. Rev. B: Condens. Matter Mater. Phys., 2010, 82, 024102.

62 A. E. Stearn and H. Hyring, J. Chem. Phys., 1937, 5, 113-124. 63 B. Bleaney and K. W. H. Stevens, Rep. Prog. Phys., 1953, 16, 108.

64 R. A. Eichel, Phys. Chem. Chem. Phys., 2011, 13, 368.

65 D. T. Edwards, Y. Zhang, S. J. Glaser, S. Hancd and M. S. Sherwin, Phys. Chem. Chem. Phys., 2013, 15, 5707.

66 M. Shivram, R. H. Krishna, H. Nagabhushana, S. C. Sharma, B. M. Nagabhushana, B. S. Ravikumar, N. Dhananjaya, C. Shivakumara, J. L. Rao and R. P. S. Chakradhar, Mater. Res. Bull., 2013, 48, 1490.

67 X. J. Luo, Y. S. Liu, C. P. Yang, S. S. Chen, S. L. Tang and K. Bärner, J. Eur. Ceram. Soc., 2015, 35, 2073.

68 J. Milanez, A. T. de Figueiredo, S. de Lazaro, V. M. Longo, R. Erlo, V. R. Mastelaro, R. W. A. Franco, E. longo and J. A. Varela, J. Appl. Phys., 2009, 106, 043526.

69 E. Possenriede, P. Jacobs and O. F. Schirmer, J. Phys.: Condens. Matter, 1992, 4, 4719.

70 G. Pinarello, C. Pisani, A. D'Ercole, M. Chiesa, M. C. Paganini, E. Giamello and O. Diwald, Surf. Sci., 2001, 494, 95.
71 P. Boutinaud, E. Pinel, M. Dubois, A. P. Vink and R. Mahiou, J. Lumin., 2005, 111, 69.

72 T. R. N. Kutty, P. Murugaraj and N. S. Gajbhiye, Mater. Res. Bull., 1985, 20, 565.

73 N. S. Hari, P. Padmini and T. R. N. Kutty, J. Mater. Sci.: Mater. Electron., 1997, 8, 15.

74 Q. Sun, Q. Gu, K. Zhu, R. Jin, J. Liu, J. Wang and J. Qiu, Sci. Rep., 2017, 7, 42274.

75 E. Erdem, P. Jakes and R.-A. Eichel, Funct. Mater. Lett., 2010, 3, 65.

76 R. Scharfschwerdt, A. Mazur, O. F. Schirmer, H. Hesse and S. Mendricks, Phys. Rev. B: Condens. Matter Mater. Phys., 1996, 54, 15284.

77 R. F. Howe and M. Gratzel, J. Phys. Chem., 1987, 91, 3906.

78 A. Abragam and M. H. L. Pryce, Proc. Phys. Soc., London, Sect. A, 1951, 205, 135.

79 R. H. Hoskins and B. H. Soffer, Phys. Rev. A, 1964, 490, 133. 80 F. La Mattina, J. G. Bednorz, S. F. Alvarado, A. Shengelaya, K. A. Müller and H. Keller, Phys. Rev. B: Condens. Matter Mater. Phys., 2009, 80, 075122.

81 D. V. Azamat, A. Dejneka, J. Lancok, V. A. Trepakov, L. Jastrabik and A. G. Badalyan, J. Appl. Phys., 2013, 113, 174106. 